\title{
Sedation and Paralysis
}

\author{
Annop Piriyapatsom MD, Edward A Bittner MD PhD, Jessica Hines MA, \\ and Ulrich $\mathrm{H}$ Schmidt MD PhD
}

\author{
Introduction \\ Protocolized Sedation Algorithms \\ Monitoring Sedation in Critically Ill Patients \\ Drugs for Sedation in the ICU \\ Concept of Minimal or "No" Sedation \\ Role of Paralysis and NMBAs in the ICU \\ Choice of NMBAs and Monitoring Depth of Paralysis \\ Reconciling the Apparent Paradox of Benefits of Both Minimal Sedation \\ and Heavy Sedation \\ Summary
}

\begin{abstract}
Sedation is used almost universally in the care of critically ill patients, especially in those who require mechanical ventilatory support or other life-saving invasive procedures. This review will focus on the sedation strategies for critically ill patients and the pharmacology of commonly used sedative agents. The role of neuromuscular blocking agents in the ICU will be examined and the pharmacology of commonly used agents is reviewed. Finally a strategy for rational use of these sedative and neuromuscular blocking agents in critically ill patients will be proposed. Key words: sedation; sedatives; critical illness; mechanical ventilation; neuromuscular blocking agent. [Respir Care 2013;58(6):1024-1035. @ 2013 Daedalus Enterprises]
\end{abstract}

\section{Introduction}

Sedation is used almost universally in the care of critically ill patients, especially in those who require mechan-

\footnotetext{
The authors are affiliated with the Department of Anesthesia, Critical Care, and Pain Medicine, Massachusetts General Hospital, Boston, Massachusetts.

Dr Schmidt presented a version of this paper at the 51st RESPIRATORY CARE Journal Conference, "Adult Mechanical Ventilation in Acute Care: Issues and Controversies," held September 7 and 8, 2012, in St Petersburg, Florida.

The authors have disclosed no conflicts of interest.

Correspondence: Ulrich H Schmidt MD PhD, Department of Anesthesia, Critical Care, and Pain Medicine, Massachusetts General Hospital, 55 Fruit Street, Boston MA 02115. E-mail: Uschmidt@partners.org.
}

DOI: $10.4187 /$ respcare.02232 ical ventilatory support or other life-saving invasive procedures. ${ }^{1-4}$ Anxiety may occur either as a consequence of illnesses leading to ICU admission or as a result of interventions performed in the ICU, including invasive and noninvasive procedures, immobility, and routine care such as turning. In addition, anxiety may develop as a result of pain, unfamiliar environment, loss of self-control, inability to communicate, sleep disruption, or isolation. ${ }^{5}$ Both pain and anxiety can cause untoward physiological consequences, including an increase in sympathetic tone, inflammatory response, coagulation cascade, and oxygen consumption, ${ }^{3,4}$ which may contribute to organ ischemia, multi-organ failure, and death. The sedatives and analgesics used to alleviate anxiety and pain have been associated with a number of detrimental effects in critically ill patients, including increased risks of nosocomial infection, ${ }^{6} \mathrm{ICU}$-acquired weakness ${ }^{7}$ and delirium, ${ }^{7-9}$ all of which are risk factors for worsened outcome. The effect of sedation on neuropsychological outcomes has been investi- 
gated by several groups. ${ }^{10-13}$ Based on these studies there is conflicting evidence whether or not the depth of sedation impacts long-term neuropsychological outcomes. Neuromuscular blocking agents (NMBAs) are used in the ICU to improve patient-ventilator synchrony, enhance gas exchange, and diminish the risk of barotrauma. They can also be employed to reduce muscle oxygen consumption, to prevent unwanted movements in patients with increased intracranial pressure, and to facilitate treatment of acute neurologic conditions such as tetanus. However, NMBAs are also associated with potential adverse effects, including hypersensitivity reactions and ICU-acquired weakness. This review will focus on sedation strategies for critically ill patients and review the pharmacology of commonly used sedative agents. The role of NMBAs in the ICU will be examined and an algorithm for rational use of these agents will be proposed.

\section{Protocolized Sedation Algorithms}

The goal of protocolized sedation algorithms is to promote evidence-based care, to reduce variations in clinical practice, and systematically to reduce the likelihood of excessive and/or prolonged sedation. These protocols typically consist of: setting goals of analgesia and sedation for an individual patient; assessment for pain and sedation with applicable tools and frequency; and intervention to meet the goals by the multidisciplinary care terms. ${ }^{1-4} \mathrm{Be}-$ fore-and-after studies of the implementation of sedation protocols have shown a number of benefits, including a reduction in analgesic and sedatives administration, ${ }^{14-16}$ duration of mechanical ventilation, ${ }^{14,16-18}$ delirium, ${ }^{15}$ rate of nosocomial infection, ${ }^{16}$ ICU and hospital stay, ${ }^{14,18,19}$ and an improved functional status post discharge from the hospital. ${ }^{14}$ However, implementation of these protocols has not been shown to be associated with a significant decrease in mortality rate..$^{14,16-18}$ In a recent systematic review $^{20}$ of the topic, Jackson et al conclude that implementation of sedation management protocols in critically ill patients is strongly associated with a decrease in duration of mechanical ventilation, stay in ICU, and, probably, incidence of ventilator-associated pneumonia, without an increase in adverse events. Mehta et al recently published the results of a randomized controlled trial investigating whether daily interruption of sedation decreases the time to extubation in mechanically ventilated patients. ${ }^{21}$ These authors reported that in patients sedated with benzodiazepine and opioid infusions, interruption of sedation changed neither the time of mechanical ventilation nor the time to ICU discharge.

\section{Monitoring Sedation in Critically Ill Patients}

Before administering sedation to critically ill patients, adequate pain control should be assured. ${ }^{1-4}$ Patient self- report of pain is considered the standard for pain assessment ${ }^{1,2,22,23}$; however, the use of self-reporting tools is limited in mechanically ventilated, critically ill patents, especially those receiving deep sedation or paralysis. In such patients, assessment of pain by means of subjective observation of pain-related behaviors (eg, movement, facial expression, and posturing) and physiological parameters (eg, heart rate, blood pressure, and breathing frequency), as well as the change in these parameters after analgesia therapy, are recommended. ${ }^{1,23}$ Pain scales validated for use in mechanically ventilated patients include the Behavioral Pain Scale, ${ }^{24}$ the Nonverbal Pain Scale, ${ }^{25}$ and the Critical Care Pain Observation Tool. ${ }^{26}$ It is important to note that none of these scales has been validated in deeply sedated patients. ${ }^{1}$

There are a number of scales for sedation assessment in critically ill patients, but there is no true gold standard. ${ }^{1}$ Ideally, the scale should be both reliable, providing consistent assessments of sedation level when administered by different caregivers, and valid, providing good correlation with patients' true level of sedation. The Richmond Agitation-Sedation Scale (RASS) is the most extensively validated in critically ill patients and, accordingly, is the most widely used in the ICU. 2,4,22,23 Other tools attempt to make objective assessments of depth of sedation based on monitoring cerebral function or, specifically, electroencephalography. The Bispectral Index is the most widely studied processed-electroencephalography monitor for evaluation of depth of anesthesia in patients undergoing surgical procedures and for sedation in ICU patients. In brief, the Bispectral Index processes a raw electroencephalography signal obtained from a sensor at the unilateral prefrontal lobe area, and then displays as a number in the range from 0 to 100 , where 0 indicates "no cortical activity" and 100 indicates "fully awake." 22 In mechanically ventilated critically ill patients there is a good correlation between Bispectral Index values and depth of sedation measured by the clinical sedation scale in some studies, ${ }^{27-30}$ but not in others. ${ }^{31}$ The Bispectral Index value may inaccurately assess depth of sedation in paralyzed patients or those with traumatic brain injury ${ }^{27}$ and can overestimate depth of sedation in patients with high muscle activity. ${ }^{31-33}$ Until now, no cerebral function monitors are recommended to replace the clinical sedation scale for assessment of the depth of sedation in critically ill patients. ${ }^{1,22}$

\section{Drugs for Sedation in the ICU}

Benzodiazepines are commonly administrated for sedation in mechanically ventilated patients in the ICU. 34,35 These drugs act through the gamma-aminobutyric acid neuroinhibitory receptor complex in the central nervous system, causing neurons to be less excitable. ${ }^{36}$ Benzodiazepines have potent anxiolysis, sedative, and hypnotic 
effects. ${ }^{36}$ Within the benzodiazepine group, midazolam and lorazepam are the most common agents used in the ICU setting. ${ }^{1}$ Midazolam is more lipophilic than lorazepam and therefore has a more rapid onset of action and shorter duration of action after single bolus administration. However, it can accumulate in the adipose tissue after prolonged infusion, especially in patients who are obese or who have low serum albumin levels, resulting in prolonged duration of action. Midazolam is metabolized by the cytochrome P450 enzyme system in the liver, and its more water-soluble metabolites are then excreted by the kidneys. The primary metabolite of midazolam, 1-hydroxymidazolam glucuronide, has mild central nervous system depressant effects. In critically ill patients with liver and/or renal dysfunction, as well as those receiving drugs that have interaction with cytochrome P450 isoenzyme 3A4, the duration of action of this drug can be substantially prolonged. When compared with midazolam, lorazepam has slower onset and longer duration of action after single bolus dose. It is metabolized by hepatic glucuronidation to inactive metabolites that are renally excreted, making it theoretically safer than midazolam for administration in patients with renal impairment. ${ }^{36}$ Propylene glycol, the dilutent used for the intravenous form of lorazepam, and accumulation of its metabolites (ie, lactate and pyruvate) can cause a hyperosmolar state, metabolic acidosis, and acute tubular necrosis. ${ }^{36}$ When lorazepam and midazolam are used for sedation in critically ill patients for more than 24 hours, the pharmacokinetics of these drugs becomes more highly variable. ${ }^{37}$ Patient-related factors that can affect the response to benzodiazepines include age, underlying diseases such as hepatic and renal insufficiency, prior alcohol or other sedative drug use, and concurrent therapy with opioids. When compared with lorazepam, midazolam is more titratable, therefore minimizing over- or undersedation, ${ }^{38}$ has a shorter emergence time after discontinuation of an infusion, ${ }^{39}$ and is associated with a lower risk of delirium. ${ }^{40}$

Propofol is commonly administrated for sedation in the ICU. It acts on the gamma-aminobutyric acid receptor at a different binding site than benzodiazepines. It is an intravenous general anesthetic agent with sedative, hypnotic, amnestic, and anticonvulsant properties. Propofol is highly lipophilic, resulting in rapid transfer across the blood-brain barrier and thus rapid onset of action. Redistribution to peripheral tissues and a large volume of distribution lead to a rapid emergence after bolus administration. For longterm infusion in critically ill patients, however, time to recovery from propofol can vary with the depth and duration of administration, as well as the patient-related factors. ${ }^{41}$ Propofol undergoes conjugation in the liver to inactive metabolites that are excreted by the kidneys. Unlike benzodiazepines, hepatic or renal dysfunction does not substantially affect the clearance of propofol. ${ }^{1}$ Common dose-dependent adverse effects, especially after large bolus dose administration, include respiratory depression and hypotension from systemic vasodilation, and negative inotropic effects. As an oil-in-water emulsion preparation containing triglycerides, it provides a $1.1 \mathrm{kcal} / \mathrm{mL}$ caloric source, which should be included in calculation of nutritional requirements. ${ }^{36}$ Hypertriglyceridemia ${ }^{42,43}$ and hyperamylasemia ${ }^{44}$ have been reported after long-term infusion of propofol; therefore, when using propofol infusions over an extended period of time, frequent monitoring of serum triglycerides and serum amylase levels is warranted. Propofol infusion syndrome is a rare but potentially lethal adverse effect associated with prolonged administration of high-dose propofol. This clinical syndrome consists of severe metabolic acidosis, hyperkalemia, rhabdomyolysis, acute renal failure, cardiac failure, arrhythmias, and asystole. The exact mechanism of propofol infusion syndrome is unknown, but it is associated with a large cumulative propofol dose, young age, acute neurological injury, low carbohydrate intake, high fat intake, catecholamine or corticosteroid infusion, critical illness, and inborn errors of metabolism. ${ }^{45,46}$ Limiting the infusion of propofol in adult critically ill patients to a maximum rate of $4-5 \mathrm{mg} / \mathrm{kg} / \mathrm{h}$ is recommended. ${ }^{23,45,46}$

In mechanically ventilated patients the time to extubation after discontinuation of propofol infusion is substantially shorter, compared to midazolam or lorazepam. ${ }^{42,47,48}$ A recent meta-analysis of the use of propofol, compared with midazolam, in critically ill patients also shows that the duration of mechanical ventilation is significantly shorter (mean difference of $0.2 \mathrm{~d}, P<.001$ ) but has no impact on stay in the ICU. ${ }^{49}$

Dexmedetomidine is another sedative agent that is increasingly used in the ICU. Dexmedetomidine is a highly selective alpha-2 agonist that acts through the presynaptic neurons in the locus coeruleus and spinal cord, causing a decrease in central nervous system sympathetic outflow. It has anxiolytic, sedative, and analgesic properties, without causing clinically relevant respiratory depression. The patient's level of arousal is maintained at deep levels of sedation with dexmedetomidine, resulting in a so-called "cooperative sedation." 50 Dexmedetomidine is primarily metabolized in the liver, through glucuronide conjugation, and biotransformation in the cytochrome P450 enzyme system, without active metabolites. Renal impairment does not significantly affect the pharmacokinetics. ${ }^{51}$ In the elderly and patients with hypoalbuminemia the clearance of dexmedetomidine may be prolonged. ${ }^{52}$ The major cardiovascular adverse effects of this agent result from its sympatholytic properties, resulting in bradycardia, transient hypertension after the rapid initial loading dose, and hypotension during continuous infusion. At present, the FDA has approved dexmedetomidine for continuous infusion in 
mechanically ventilated patients for up to 24 hours ${ }^{53}$; however, safe use over longer periods has been reported. ${ }^{54}$

In a randomized double-blind controlled trial comparing infusions of dexmedetomidine versus lorazepam in mechanically ventilated patients, Pandharipande et $\mathrm{al}^{55}$ concluded that sedation with dexmedetomidine was associated with more days alive without cerebral dysfunction, namely delirium and coma ( $7 \mathrm{~d}$ vs $3 \mathrm{~d}, P=.01$ ), and lower prevalence of cerebral dysfunction ( $87 \%$ vs $98 \%, P=.03$ ). Patients sedated with dexmedetomidine also spent more time at their targeted RASS sedation level. There were no significant differences between groups in terms of adverse events, including self-extubation ( $8 \%$ vs $4 \%, P=.41$ ), although more patients receiving dexmedetomidine experienced sinus bradycardia ( $17 \%$ vs $4 \%, P=.03$ ). In a subgroup of septic patients, ${ }^{56}$ those sedated with dexmedetomidine had significantly more delirium-free days $(8.1 \mathrm{~d}$ vs $6.7 \mathrm{~d}, P=.06$ ), coma-free days ( $9.4 \mathrm{~d}$ vs $5.9 \mathrm{~d}, P<.001$ ), and mechanical-ventilation-free days $(15.2 \mathrm{~d}$ vs $10.1 \mathrm{~d}$, $P=.03$ ). Twenty-eight-day mortality was also significantly lower in septic patients treated with dexmedetomidine, when compared with those receiving lorazepam $(16 \%$ vs $41 \%, P=.03) .56$

The efficacy of dexmedetomidine for long-term sedation, compared with midazolam, has been investigated in 2 recent multicenter double-blind randomized trials. Riker and colleagues ${ }^{57}$ randomized 375 medical and surgical patients who were expected to require mechanical ventilation for more than 24 hours to receive either dexmedetomidine or midazolam with a target RASS score between -2 and +1 . They found no significant difference in the time spent within the target RASS score range $\mathbf{7 7 . 3 \%}$ in dexmedetomidine group vs $75.1 \%$ in midazolam group, $P=.18)$. However, patients sedated with dexmedetomidine had significantly shorter time to extubation ( $3.7 \mathrm{~d}$ vs $5.6 \mathrm{~d}, P=.01$ ) as well as a lower prevalence of delirium (54\% vs $76.6 \%, P<.001$ ). Dexmedetomidine-treated patients were more likely to develop bradycardia $(42.2 \%$ vs $18.9 \%, P<.001$ ), with no significant increase in the proportion requiring treatment $(4.9 \%$ vs $0.8 \%, P=.07)$, but had a lower likelihood of tachycardia (25.4\% vs $44.3 \%$, $P<.001)$ or hypertension requiring treatment $(18.9 \%$ vs $29.5 \%, P=.02$ ). There was no significant difference in 30 -day mortality rate $22.5 \%$ in dexmedetomidine group vs $25.4 \%$ in midazolam group, $P=.60$ ). Jakob et al ${ }^{58}$ reported the results of a multicenter randomized doubleblind trial of adult ICU patients receiving either dexmedetomidine or midazolam for mechanical ventilation lasting more than 24 hours. The study found no significant difference in the time spent at the target RASS range of 0 to $-3(60.7 \%$ in the dexmedetomidine group vs $56.6 \%$ in the midazolam group, $P=.15$ ). Patients sedated with dexmedetomidine had a significantly shorter duration of mechanical ventilation (123 h vs $164 \mathrm{~h}$ in the midazolam group, $P=.03)$ and time to extubation $(101 \mathrm{~h}$ vs $147 \mathrm{~h}$, $P=.01)$. In addition, patients sedated with dexmedetomidine were also better able to interact during nursing care and to communicate their pain than those sedated with midazolam. There was no significant difference in stay in the ICU or hospital, in the rate of neurocognitive impairment, or in mortality between the 2 groups. As in the study by Riker et al, more patients in the dexmedetomidine group developed hypotension $(20.6 \%$ vs $11.6 \%$ in the midazolam group, $P=.007)$ and bradycardia $(14.2 \%$ vs $5.2 \%$, $P<.001)$. To evaluate the cost of sedation with dexmedetomidine, compared with midazolam, for sedation in the ICU, Dasta and co-workers ${ }^{59}$ performed a cost-minimization analysis of the data reported by Riker et al. They concluded that sedation with dexmedetomidine, when compared with midazolam, was associated with a reduction in total ICU cost, which resulted primarily from the reduced duration of ICU stay and time requiring mechanical ventilation.

The comparison of dexmedetomidine to propofol in the ICU has also undergone recent investigation. In a multicenter randomized trial, Jakob et al compared the efficacy of dexmedetomidine versus propofol for long term sedation in 498 mechanically ventilated patients in the ICU. ${ }^{58}$ The primary outcome was to determine whether dexmedetomidine was non-inferior to propofol for maintaining a level of sedation (target RASS range between 0 and -3 ). The authors found no significant difference between groups in the time spent in the target RASS range $(64.6 \%$ for dexmedetomidine group vs $64.7 \%$ for propofol group, $P=.97)$ or duration of mechanical ventilation $(97 \mathrm{~h}$ vs $118 \mathrm{~h}, P=.24)$, although the time to extubation was significantly less in the dexmedetomidine group $(69 \mathrm{~h}$ vs $93 \mathrm{~h}, P=.04)$. There was also no significant difference in stay in the ICU or in the hospital, and no difference in the mortality rate between groups. Patients sedated with dexmedetomidine had better ability to communicate their pain and cooperate in nursing care than those sedated with propofol. Although the rate of cardiovascular adverse events was similar in both groups, more patients sedated with propofol developed critical illness polyneuropathy (11 patients vs 2 patients in the dexmedetomidine group, $P=.02$ ) and more experienced neurocognitive adverse events (29\% vs $18 \%, P=.008)$. The Table summarizes characteristics of these sedatives.

\section{Concept of Minimal or “No" Sedation}

There is increasing evidence that continuous infusion of sedatives may contribute to the prolongation of mechanical ventilation and ICU stay and increase the risk of morbidity and mortality. ${ }^{60}$ In 2000 , Kress et al ${ }^{61}$ first described the concept of "daily interruption of sedation" in a randomized controlled trial of adult mechanically ventilated 


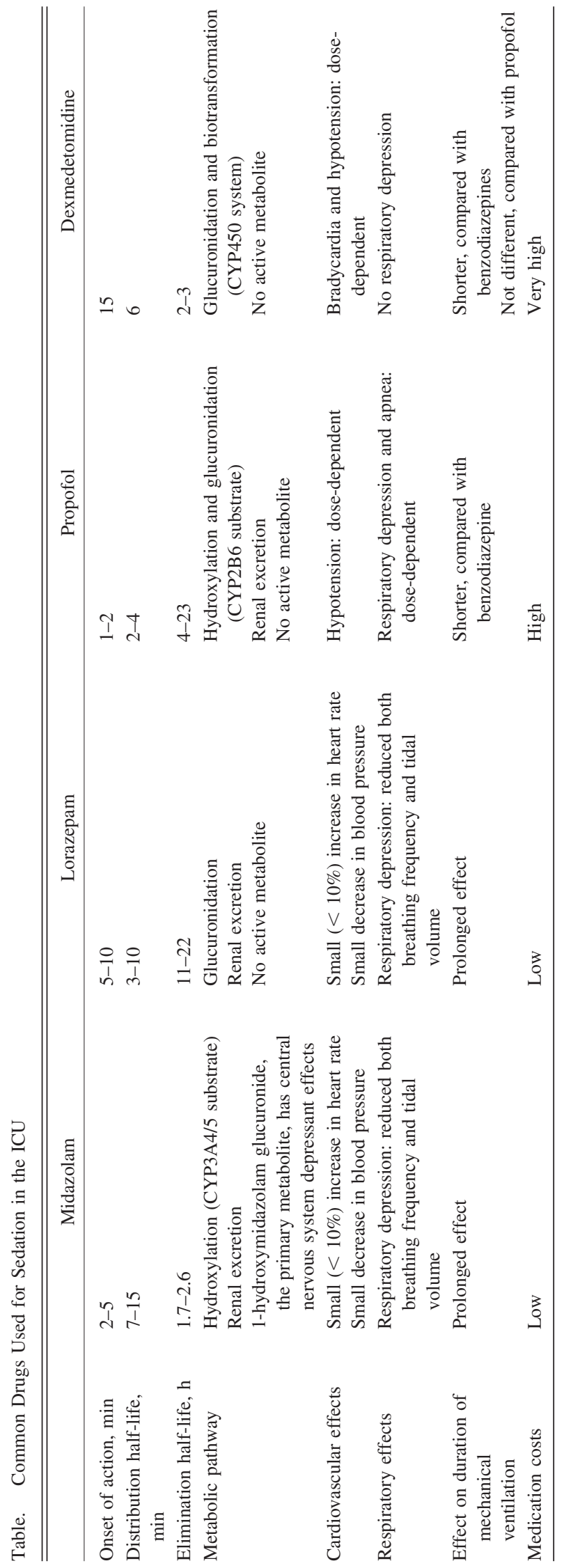

medical ICU patients who were receiving continuous infusions of sedative drugs. In the intervention group, on a daily basis, the sedative infusions were interrupted until the patients were awake. In the control group the infusions were interrupted only at the discretion of the clinicians in the ICU. The trial found that the duration of mechanical ventilation and ICU stay were significantly shorter in the group that underwent daily interruption of sedation $(2.4 \mathrm{~d}$ and $3.5 \mathrm{~d}, P=.004$ and .02 , respectively). There was no significant difference in the rates of adverse events or mortality between groups (in-hospital mortality rate of $36 \%$ in the intervention group vs $46.7 \%$ in the control group, $P=.25$ ). A subsequent retrospective analysis ${ }^{62}$ of their data revealed reduced numbers of ICU complications (eg, ventilator-associated pneumonia, upper gastrointestinal hemorrhage, bacteremia, barotraumas, venous thromboembolic disease, cholestatis, and sinusitis) in the patients who received daily interruption of sedation $(2.8 \%$ vs $6.2 \%$, $P=.04)$.

The benefits of interrupting sedation in ICU patients have been shown to be even more profound when combined with a daily spontaneous breathing trial (SBT). In the Awakening and Breathing Controlled Trial, Girard et al ${ }^{63}$ randomly assigned 336 mechanically ventilated ICU patients to management with daily awakening, followed by an SBT (intervention group) or with sedation per usual care plus a daily SBT (control group). The primary end point was time to breathing without assistance. When compared with the control group who received an SBT with sedation per usual care, the intervention group had a significantly lower mortality rate during the first year after enrollment (hazard ratio $0.68,95 \%$ CI $0.50-0.92, P=.01$ ). In addition, the intervention group had significantly more ventilator-free days ( $14.7 \mathrm{~d}$ vs $11.6 \mathrm{~d}, P=.02)$ and shorter ICU stay $(9.1 \mathrm{~d}$ vs $12.9 \mathrm{~d}, P=.01)$ and hospital stay ( $14.9 \mathrm{~d}$ vs $19.2 \mathrm{~d}, P=.04)$. Of note there was a significantly higher rate of self-extubation in the intervention group (10\% vs $4 \%, P=.03$ ), although other complications, including delirium and coma, were not significantly different between groups. Long-term cognitive, psychological, and functional outcomes were subsequently reported for the daily interruption of sedation studies by Kress et al and Girard et al. There was no increase in adverse long-term outcomes in patients who received daily interruption of sedation during their ICU stay, including no increase in the incidence of post-traumatic stress disorder. ${ }^{12,64}$

Several recent studies have examined whether combining daily interruption of sedation with physical and occupational therapy can reduce long-term complications of critical illness such as ICU-acquired weakness and neuropsychiatric disease. ${ }^{65,66} \mathrm{In}$ a randomized controlled trial by Schweickert et al, ${ }^{65} 104$ mechanically ventilated patients in the ICU were randomly assigned to early exercise and 
mobilization (physical and occupational therapy) during periods of daily interruption of sedation (intervention) or to daily interruption of sedation with therapy as ordered by the primary care team (control). Patients in the intervention group received earlier physical and occupational therapy than those in the control group (within $1.5 \mathrm{~d}$ after intubation vs $7.4 \mathrm{~d}, P<.001$ ). In addition, significantly more patients in the intervention group returned to independent functional status at hospital discharge $(59 \%$ vs $35 \%$ in the control group, $P=.02$ ). Duration of delirium and mechanical ventilation were also significantly shorter in the intervention group ( $2 \mathrm{~d}$ vs $4 \mathrm{~d}$ in the control group, $P=.02$ and $3.4 \mathrm{~d}$ vs $6.1 \mathrm{~d}, P=.02$, respectively). There were no reported adverse events, including falls, accidental extubations, or pathologic changes in blood pressure, during the total 498 physical and occupational therapy sessions, except limited episodes of desaturation. There was no significant difference in stay in ICU and in hospital, as well as hospital mortality rate between groups.

A "no sedation strategy" was studied by Strøm et al ${ }^{67}$ in a trial of 140 critically ill adult patients who were randomized to receive either no sedation or sedation $(20 \mathrm{mg} / \mathrm{mL}$ propofol for $48 \mathrm{~h}, 1 \mathrm{mg} / \mathrm{mL}$ midazolam thereafter) with daily interruption until awake (control group). Both groups were treated with bolus doses of morphine ( 2.5 or $5 \mathrm{mg}$ ). The primary outcomes were the number of days without mechanical ventilation in a 28-day period, and ICU and hospital stay. Patients receiving no sedation, when compared to those with daily interruption of sedation, had more ventilator-free days ( $13.8 \mathrm{~d}$ vs $9.6 \mathrm{~d}, P=.02)$, shorter ICU stay (13.1 d vs $22.8 \mathrm{~d}, P=.03$ ), and shorter hospital stay ( $34 \mathrm{~d}$ vs $58 \mathrm{~d}, P=.004$ ). Hyperactive delirium occurred more frequently in the no sedation group, when compared to sedation group ( $20 \%$ vs $7 \%, P=.04)$. On first glance this finding might be surprising. However, it might be that sedation merely suppressed the signs of hyperactive delirium. The authors did not report the incidence of hypoactive delirium, and other complications (eg, accidental endotracheal tube removal, reintubation rate within $24 \mathrm{~h}$, ventilator-associated pneumonia, need for brain imaging scan) were not significantly increased. Important considerations when evaluating whether the results of this study can be generalized to other ICU environments include the high staffing ratio utilized during the study, including a nurse to patient ratio of $1: 1$ and the presence of an additional person to comfort and reassure patients as needed.

\section{Role of Paralysis and NMBAs in the ICU}

NMBAs are used in the ICU to improve patient-ventilator synchrony, enhance gas exchange, and diminish the risk of barotrauma. The most common reason for NMBA administration is to facilitate mechanical ventilatory sup-
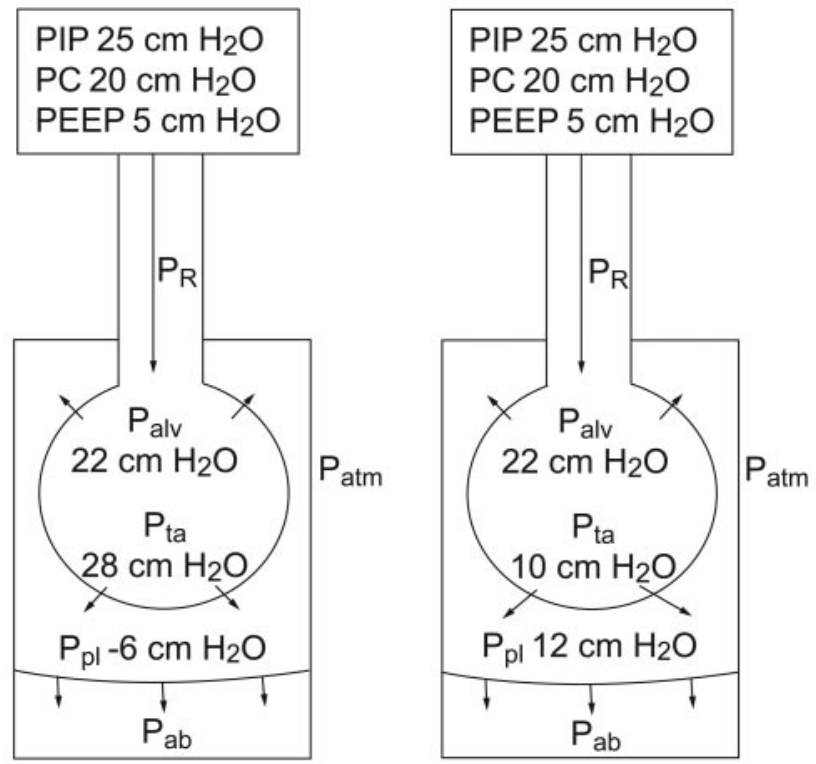

Fig. 1. Transpulmonary pressures in a spontaneously breathing patient and in a patient on a neuromuscular blocking agent (NMBA). $\mathrm{PIP}=$ peak inspiratory pressure. $\mathrm{PC}=$ pressure control. $\mathrm{P}_{\mathrm{R}}=$ pressure drop due to airways resistance. $\mathrm{P}_{\mathrm{alv}}=$ alveolar pressure. $\mathrm{P}_{\mathrm{atm}}=$ atmospheric pressure. $\mathrm{P}_{\mathrm{ta}}=$ transalveolar pressure. $\mathrm{P}_{\mathrm{pl}}=$ pleural pressure. $P_{a b}=$ abdominal pressure. (From Reference 74.)

port. Administration of NMBAs eliminates the spontaneous breathing activity, thereby allowing tidal volume and the plateau pressure to be controlled within desirable target ranges. ${ }^{68-70}$ The use of NMBAs is especially helpful during non-conventional ventilatory strategies such as permissive hypercapnia, prone positioning, use of high levels of PEEP, and high frequency oscillatory ventilation. ${ }^{71-73} \mathrm{In}$ addition, elimination of spontaneous inspiratory efforts reduces transpulmonary pressures, thereby potentially minimizing the risk of overstretch and strain on alveoli, compared with patients making vigorous inspiratory efforts ${ }^{74,75}$ (Fig. 1). Others indications for NMBA administration include management of increased intracranial pressure, treatment of refractory status asthmaticus, reduction of oxygen consumption, and prevention of shivering in patients receiving therapeutic hypothermia after cardiac arrest. 76,77 Given these potential benefits, the use of NMBAs is not an uncommon practice in critically ill patients.

A large multicenter, international observation study ${ }^{72}$ reported that $13 \%$ of mechanically ventilated patients received NMBAs for at least 1 day. In some groups of critically ill patients, such as those with acute lung injury/ ARDS, the prevalence of NMBA use might be as high as $25-45 \% .^{78} \mathrm{ICU}$-acquired weakness is a potential adverse event that may be associated with prolonged use of NMBAs, especially when corticosteroids are simultaneously administrated, or in patients with systemic inflammatory response or sepsis. ${ }^{79-83}$ The prevalence of ICU-acquired weakness 
in critically ill patients is estimated to be in the range of 25-30\%.83-86 The development of ICU-acquired weakness contributes to longer duration of mechanical ventilation, longer ICU and hospital stay, as well as higher mortality rate, ${ }^{83,85,86}$ when compared to critically ill patients who do not develop ICU-acquired weakness. Although the etiology of ICU-acquired weakness is most likely multifactorial, it has been suggested that prolonged use of NMBAs may result in accumulation of active metabolites, especially in critically ill patients with impaired hepatic and/or renal function, alteration in the acetylcholine receptor function at the neuromuscular junction, or NMBA-induced channel block. ${ }^{82}$ These factors may be responsible for prolonged weakness after discontinuation of sustained NMBA administration.

Another adverse event potentially related with the use of NMBAs is ventilator-induced diaphragmatic dysfunction. ${ }^{87,88}$ Levine et al ${ }^{89}$ examined biopsy specimens of the diaphragm obtained from mechanically ventilated, braindead organ donors, and found that diaphragmatic atrophy developed within a period of only 18-96 hours without diaphragmatic activity, compared with the specimens where diaphragmatic inactivity was limited to $2-3$ hours. Ventilator-induced diaphragmatic dysfunction may result in prolonged mechanical ventilatory support, weaning failure, and increased morbidity and mortality. ${ }^{87,88}$ In animal models, maintenance of spontaneous diaphragm activity during mechanical ventilator support has been shown to reduce the development and severity of ventilator-induced diaphragmatic dysfunction. ${ }^{68,69,87}$

Some evidence suggests that administration of NMBAs may be beneficial in mechanically ventilated patients with severe hypoxic respiratory failure or ARDS. Forel et al ${ }^{90}$ randomized 36 patients with ARDS to receive conventional therapy (tidal volume between 4 and $8 \mathrm{~mL} / \mathrm{kg}$ ideal body weight, plateau pressure of $\leq 30 \mathrm{~cm} \mathrm{H}_{2} \mathrm{O}$ ) plus placebo, or conventional therapy plus NMBAs for 48 hours. In this study, systemic and pulmonary inflammatory response was attenuated, as indicated by decreases in both alveolar and serum concentrations of cytokines (eg, interleukin-6 and interleukin-9) after short-term administration of NMBAs. In addition, an improvement in the $\mathrm{P}_{\mathrm{aO}_{2}} / \mathrm{F}_{\mathrm{IO}_{2}}$ and decreases in peak and plateau pressures were also observed after NMBA administration. These effects were substantially sustained after discontinuation of NMBAs. ${ }^{90,91}$ In a small study of critically ill patients with respiratory failure, Marik and Kaufman ${ }^{92}$ found that administration of NMBAs significantly decreased oxygen consumption $\left(537 \pm 139 \mathrm{~mL} / \mathrm{min} / \mathrm{m}^{2}\right.$ at baseline vs $471 \pm 95 \mathrm{~mL} /$ $\mathrm{min} / \mathrm{m}^{2}$ post paralysis, $P=.03$ ) and significantly improved splanchnic ischemia, as evidenced by the rise in gastric intramucosal $\mathrm{pH}(7.21 \pm 0.16$ vs $7.29 \pm 0.1, P=.02)$. The authors suggested that by eliminating the work of breathing there is a redistribution of blood flow from the respiratory muscles to the splanchnic and other non-vital vascular beds.

In a recent multicenter randomized controlled trial by Papazian et al, ${ }^{93} 340$ mechanically ventilated patients within the early phase of ARDS were randomly assigned to receive cisatracurium, for a period of 48 hours, or placebo. The primary outcomes of the study were in-hospital and the 90-day mortality. Patients in the cisatracurium group had lower adjusted 90-day mortality (adjusted hazard ratio $0.68,95 \%$ CI $0.48-0.98, P=.04$ ), when compared with the control group. In addition, patients in the cisatracurium group had significantly more ventilator-free and organfailure-free days, as well as more days outside the ICU, when compared with those in the control group. Meanwhile, there was no significant difference between groups with regard to the incidence of ICU-acquired paresis. The postulated explanations for these remarkable results include a direct anti-inflammatory effect of cisatracurium, and the beneficial effects of minimizing ventilator-induced lung injury, decreasing oxygen consumption, and improving oxygenation.

\section{Choice of NMBAs and Monitoring Depth of Paralysis}

NMBAs commonly administrated for long-term use in the ICU are subdivided into 2 groups: aminosteroid and benzylisoquinoline NMBAs. Structurally, the aminosteroidal NMBAs have at least one quaternary ammonium group attached to a steroid nucleus. Agents belonging to the aminosteroid group are pancuronium, vecuronium, and rocuronium. Pancuronium was formerly the most commonly used NMBA in the ICU. It has vagolytic effects that may result in tachycardia and hypertension. Consequently, pancuronium may not be suitable for use in patients at risk of myocardial ischemia. ${ }^{76,77}$ Vecuronium is a structural ana$\log$ of pancuronium, with shorter duration of action and no vagolytic effect. Both pancuronium and vecuronium are metabolized by the liver to active metabolites, which are subsequently excreted by the kidneys. Patients with hepatic and/or renal impairment may experience prolonged neuromuscular blockade, due to a decrease in clearance. Rocuronium has a short onset of action and a variable half life. In patients with hepatic dysfunction, rocuronium may cause prolonged paralysis, since it is mainly cleared by the liver. ${ }^{77}$

The other sub-group of NMBAs is the benzylisoquinoline group. Atracurium and cisatracurium are the agents of this subgroup currently used in clinical practice. Structurally, these agents are composed of 2 quaternary ammonium groups attached to a chain of methyl groups. The elimination of these drugs is independent of hepatic or renal function, which makes them particularly suitable for administration in critically ill patients with multi-organ dysfunction. ${ }^{77}$ High-dose and rapid bolus administration 
of atracurium can cause release of histamine, resulting in hemodynamic disturbances in some patients. Metabolism of atracurium occurs by nonenzymatic, Hofmann degradation, and by ester hydrolysis in the plasma. Atracurium's metabolite, laudanosine, a metabolite of atracurium with neuroexcitatory properties, may rarely cause seizures, especially in patients with hepatic and/or renal failure after prolonged administration. ${ }^{94}$ Cisatracurium is the R-cis R'CIS isomer of atracurium. Unlike atracurium, cisatracurium does not cause histamine release, and its metabolism results in one fifth of plasma concentration of laudanosine, when compared with atracurium. ${ }^{95}$

At present, there are limited data to support the use of one NMBA over another in critically ill patients. ${ }^{76,96}$ Due to its low cost and long duration of action, pancuronium has been the recommended drug for pharmacologic paralysis in critically ill patients, except in those patients where the vagolytic effect of this agent might be detrimental. ${ }^{76,96}$ Similarities in the structure of aminosteroid NMBAs and corticosteroids have raised concern in the past for an increased incidence of ICU-acquired weakness after prolonged administration. However, the use of benzylisoquinoline NMBAs has also been associated with this adverse event. ${ }^{79,96,97}$ In considering recovery of neuromuscular function after discontinuation of NMBAs, the benzylisoquinoline class may be advantageous, due to their lack of dependence on end-organ metabolism, especially in critically ill patients with impaired hepatic and/or renal function. ${ }^{96,98}$ It is worth noting that short-term infusion of cisatracurium ( $48 \mathrm{~h}$ ) was used in all 3 of the recent randomized controlled trials demonstrating an improvement in outcomes in critically ill patients with early phase ARDS.

The depth of pharmacologic paralysis should be monitored and targeted to the clinical need (ie, ventilator synchrony). ${ }^{76}$ Methods for clinical assessment of the adequacy of paralysis include observation of skeletal muscle movement, signs of respiratory efforts, ventilator asynchrony, elevated peak airway pressure, inspiratory triggering on the ventilator, or "notching" of the end-tidal carbon dioxide waveform. Monitoring the train of 4 using a peripheral nerve stimulator is considered to be the easiest and most reliable electrical measure to monitor the depth of neuromuscular blockade. ${ }^{97,99}$ Using this approach, 4 equal electrical discharges generated by the nerve stimulator device are delivered to a superficial (usually ulnar) nerve, and the contraction of the muscle is subsequently recorded. As compared to peripheral muscles, the diaphragm is more resistant to paralysis by NMBAs, ${ }^{100,101}$ thus making assessment of diaphragmatic paralysis more difficult. Several investigators have evaluated the benefits of monitoring the depth of neuromuscular blockade by the train of 4 . Rudis et al ${ }^{102}$ demonstrated that, in comparison with clinical assessment of the depth of vecuronium-induced therapeutic paralysis, train-of- 4 monitoring appears to be as- sociated with decreased total drug doses and faster recovery time of neuromuscular function after discontinuation of vecuronium. In contrast, a study by Prielipp et al ${ }^{98}$ found that the use of train-of- 4 monitoring did not prevent prolonged recovery time after cessation of vecuronium infusion. In addition, in patients receiving cisatracurium-induced paralysis, train-of-4 monitoring is not associated with lower total drug dosage or faster recovery time, when compared to monitoring by clinical assessment. ${ }^{103}$

\section{Reconciling the Apparent Paradox of Benefits of Both Minimal Sedation and Heavy Sedation (With Paralysis)}

Both minimal sedation and paralysis (with heavy sedation) have been shown to improve outcome in subgroups of critically ill patients, ${ }^{65-67,93}$ but how can 2 management strategies so diametrically opposed both be beneficial? To resolve this potential conundrum, consideration of the type and severity of disease and time course may be helpful in guiding decision making. With high severity of illness, especially in ARDS, high transpulmonary pressures aggravated by spontaneous respirations might be especially harmful. The detrimental effects of strong spontaneous inspiratory efforts increasing transpulmonary pressure may increase ventilator-induced lung injury, as illustrated by an experimental animal model of acute lung injury. ${ }^{104}$ Lavage-injured rabbits were randomly assigned to one of 4 ventilation protocols: either low $(6 \mathrm{~mL} / \mathrm{kg})$ or moderate (7-9 $\mathrm{mL} / \mathrm{kg}$ ) tidal volume ventilation combined with either weak or strong spontaneous breathing effort. Ventilation was controlled within the assigned tidal volume, and the plateau pressure maintained below $30 \mathrm{~cm} \mathrm{H}_{2} \mathrm{O}$. After 4 hours the group of rabbits ventilated with moderate tidal volume and strong spontaneous breathing effort were found to have the highest neutrophil count in the bronchoalveolar lavage fluid, as well as the highest histological lung injury scores. In the early stages of ARDS it might be beneficial to control ventilation to minimize side effects. Indeed, Papazian ${ }^{93}$ et al reported a significantly lower rate of pneumothoraces in patients who received NMBAs for 48 hours, in addition to decreased mortality. Following the acute stage of ARDS, the benefits of reduced or no sedation may be more important. This was the approach taken by Strøm et al. In their study the patients were sedated for 24 hours before being randomized to sedation and no sedation, which provided a period of time for stabilization before management with a no sedation protocol. ${ }^{67}$

Barr et all recently published practice guidelines for the treatment of pain, agitation, and delirium in critically ill patients. ${ }^{105}$ These guidelines emphasize the need for wake-up trials and light sedation. To achieve these goals there is an emphasis on the use of dexmedetomidine. While this approach may benefit the majority of patients, it does 




Fig. 2. Potential timeline of paralysis and sedation in ventilated critically ill patients.

not take timing and severity of disease into account. The first 24-48 hours of critical illness are often associated with severe physiologic and metabolic derangements in our sickest patients. During this period, deep sedation and sometimes paralysis are often needed. Dexmedetomidine and light sedation are often inadequate to facilitate mechanical ventilation and allow other invasive interventions in this setting. A 2 stage approach, with a period of initial stabilization that includes paralysis with deep sedation, followed by a non-sedation period with aggressive physical therapy, might combine the benefits of both approaches, leading to improved outcomes for our critically ill mechanically ventilated patients (Fig. 2). However, further studies of this approach are needed to help resolve the paralysis/no paralysis paradox.

\section{Summary}

On the onset of respiratory failure, deep sedation and even paralysis are often needed. After initial stabilization during the recovery phase, a sedation regimen that emphasizes light sedation, spontaneous awakening, and physical therapy may improve short-term outcomes and decrease long-term complications, including the risk of cognitive decline.

\section{REFERENCES}

1. Jacobi J, Fraser GL, Coursin DB, Riker RR, Fontaine D, Wittbrodt ET, et al. Clinical practice guidelines for the sustained use of sedatives and analgesics in the critically ill adult. Crit Care Med 2002; 30(1):119-141.

2. Patel SB, Kress JP. Sedation and analgesia in the mechanically ventilated patient. Am J Respir Crit Care Med 2012;185(5):486497.

3. McGrane S, Pandharipande PP. Sedation in the intensive care unit. Minerva Anestesiol 2012;78(3):369-380.

4. Brush DR, Kress JP. Sedation and analgesia for the mechanically ventilated patient. Clin Chest Med 2009;30(1):131-141.
5. Nelson JE, Meier DE, Oei EJ, Nierman DM, Senzel RS, Manfredi PL, et al. Self-reported symptom experience of critically ill cancer patients receiving intensive care. Crit Care Med 2001;29(2):277282.

6. Nseir S, Makris D, Mathieu D, Durocher A, Marquette CH. Intensive care unit-acquired infection as a side effect of sedation. Crit Care 2010;14(2):R30.

7. Banerjee A, Girard TD, Pandharipande P. The complex interplay between delirium, sedation, and early mobility during critical illness: applications in the trauma unit. Curr Opin Anaesthesiol 2011; 24(2):195-201.

8. Jones SF, Pisani MA. ICU delirium: an update. Curr Opin Crit Care 2012;18(2):146-151.

9. Ouimet S, Kavanagh BP, Gottfried SB, Skrobik Y. Incidence, risk factors and consequences of ICU delirium. Intensive Care Med 2007;33(1):66-73.

10. Treggiari MM, Romand JA, Yanez ND, Deem SA, Goldberg J, Hudson L, et al. Randomized trial of light versus deep sedation on mental health after critical illness. Crit Care Med 2009;37(9):25272534.

11. Samuelson K, Lundberg D, Fridlund B. Memory in relation to depth of sedation in adult mechanically ventilated intensive care patients. Intensive Care Med 2006;32(5):660-667.

12. Kress JP, Gehlbach B, Lacy M, Pliskin N, Pohlman AS, Hall JB. The long-term psychological effects of daily sedative interruption on critically ill patients. Am J Respir Crit Care Med 2003;168(12): 1457-1461.

13. Samuelson KA, Lundberg D, Fridlund B. Stressful experiences in relation to depth of sedation in mechanically ventilated patients. Nurs Crit Care 2007;12(2):93-104.

14. Mascia MF, Koch M, Medicis JJ. Pharmacoeconomic impact of rational use guidelines on the provision of analgesia, sedation, and neuromuscular blockade in critical care. Crit Care Med 2000;28(7): 2300-2306

15. Skrobik Y, Ahern S, Leblanc M, Marquis F, Awissi DK, Kavanagh BP. Protocolized intensive care unit management of analgesia, sedation, and delirium improves analgesia and subsyndromal delirium rates. Anesth Analg 2010;111(2):451-463.

16. Chanques G, Jaber S, Barbotte E, Violet S, Sebbane M, Perrigault $\mathrm{PF}$, et al. Impact of systematic evaluation of pain and agitation in an intensive care unit. Crit Care Med 2006;34(6):1691-1699.

17. De Jonghe B, Bastuji-Garin S, Fangio P, Lacherade JC, Jabot J, Appere-De-Vecchi C, et al. Sedation algorithm in critically ill patients without acute brain injury. Crit Care Med 2005;33(1):120127.

18. Quenot JP, Ladoire S, Devoucoux F, Doise JM, Cailliod R, Cunin $\mathrm{N}$, et al. Effect of a nurse-implemented sedation protocol on the incidence of ventilator-associated pneumonia. Crit Care Med 2007; 35(9):2031-2036.

19. Elliott R, McKinley S, Aitken LM, Hendrikz J. The effect of an algorithm-based sedation guideline on the duration of mechanical ventilation in an Australian intensive care unit. Intensive Care Med 2006;32(10):1506-1514.

20. Jackson DL, Proudfoot CW, Cann KF, Walsh T. A systematic review of the impact of sedation practice in the ICU on resource use, costs and patient safety. Crit Care 2010;14(2):R59.

21. Mehta S, Burry L, Cook D, Fergusson D, Steinberg M, Granton J, et al. Daily sedation interruption in mechanically ventilated critically ill patients cared for with a sedation protocol: a randomized controlled trial. JAMA 2012;308(19):1985-1992.

22. Sessler CN, Grap MJ, Ramsay MA. Evaluating and monitoring analgesia and sedation in the intensive care unit. Crit Care 2008; 12(Suppl 3):S2. 


\section{Sedation AND Paralysis}

23. Martin J, Heymann A, Bäsell K, Baron R, Biniek R, Bürkle H, et al. Evidence and consensus-based German guidelines for the management of analgesia, sedation and delirium in intensive care: short version. Ger Med Sci 2010;8:Doc02.

24. Payen JF, Bru O, Bosson JL, Lagrasta A, Novel E, Deschaux I, et al. Assessing pain in critically ill sedated patients by using a behavioral pain scale. Crit Care Med 2001;29(12):2258-2263.

25. Odhner M, Wegman D, Freeland N, Steinmetz A, Ingersoll GL. Assessing pain control in nonverbal critically ill adults. Dimens Crit Care Nurs 2003;22(6):260-267.

26. Gélinas C, Fillion L, Puntillo KA, Viens C, Fortier M. Validation of the critical-care pain observation tool in adult patients. Am J Crit Care 2006;15(4):420-427.

27. Ogilvie MP, Pereira BM, Ryan ML, Gomez-Rodriguez JC, Pierre EJ, Livingstone AS, et al. Bispectral index to monitor propofol sedation in trauma patients. J Trauma 2011;71(5):1415-1421.

28. Turkmen A, Altan A, Turgut N, Vatansever S, Gokkaya S. The correlation between the Richmond agitation-sedation scale and bispectral index during dexmedetomidine sedation. Eur J Anaesthesiol 2006;23(4):300-304.

29. Doi M, Morita K, Mantzaridis H, Sato S, Kenny GN. Prediction of responses to various stimuli during sedation: a comparison of three EEG variables. Intensive Care Med 2005;31(1):41-47.

30. Deogaonkar A, Gupta R, DeGeorgia M, Sabharwal V, Gopakumaran $\mathrm{B}$, Schubert A, et al. Bispectral Index monitoring correlates with sedation scales in brain-injured patients. Crit Care Med 2004; 32(12):2403-2406

31. Tonner PH, Wei C, Bein B, Weiler N, Paris A, Scholz J. Comparison of two bispectral index algorithms in monitoring sedation in postoperative intensive care patients. Crit Care Med 2005;33(3): 580-584

32. Vivien B, Di Maria S, Ouattara A, Langeron O, Coriat P, Riou B. Overestimation of Bispectral Index in sedated intensive care unit patients revealed by administration of muscle relaxant. Anesthesiology 2003;99(1):9-17.

33. Lu CH, Man KM, Ou-Yang HY, Chan SM, Ho ST, Wong CS, et al. Composite auditory evoked potential index versus bispectral index to estimate the level of sedation in paralyzed critically ill patients: a prospective observational study. Anesth Analg 2008;107(4):12901294.

34. Wunsch H, Kahn JM, Kramer AA, Rubenfeld GD. Use of intravenous infusion sedation among mechanically ventilated patients in the United States. Crit Care Med 2009;37(12):3031-3039.

35. Hewson-Conroy KM, Burrell AR, Elliott D, Webb SA, Seppelt IM, Taylor C, et al. Compliance with processes of care in intensive care units in Australia and New Zealand: a point prevalence study. Anaesth Intensive Care 2011;39(5):926-935.

36. Devlin JW, Roberts RJ. Pharmacology of commonly used analgesics and sedatives in the ICU: benzodiazepines, propofol, and opioids. Crit Care Clin 2009;25(3):431-449.

37. Swart EL, Zuideveld KP, de Jongh J, Danhof M, Thijs LG, Strack van Schijndel RM. Comparative population pharmacokinetics of lorazepam and midazolam during long-term continuous infusion in critically ill patients. Br J Clin Pharmacol 2004;57(2):135-145.

38. McCollam JS, O’Neil MG, Norcross ED, Byrne TK, Reeves ST. Continuous infusions of lorazepam, midazolam, and propofol for sedation of the critically ill surgery trauma patient: a prospective, randomized comparison. Crit Care Med 1999;27(11):2454-2458.

39. Barr J, Zomorodi K, Bertaccini EJ, Shafer SL, Geller E. A doubleblind, randomized comparison of i.v. lorazepam versus midazolam for sedation of ICU patients via a pharmacologic model. Anesthesiology 2001;95(2):286-298.

40. Pandharipande P, Shintani A, Peterson J, Pun BT, Wilkinson GR, Dittus RS, et al. Lorazepam is an independent risk factor for tran- sitioning to delirium in intensive care unit patients. Anesthesiology 2006;104(1):21-26

41. Barr J, Egan TD, Sandoval NF, Zomorodi K, Cohane C, Gambus $\mathrm{PL}$, et al. Propofol dosing regimens for ICU sedation based upon an integrated pharmacokinetic-pharmacodynamic model. Anesthesiology 2001;95(2):324-333.

42. Barrientos-Vega R, Sanchez-Soria MM, Morales-Garcia C, CuenaBoy R, Castellano-Hernandez M. Pharmacoeconomic assessment of propofol 2\% used for prolonged sedation. Crit Care Med 2001; 29(2):317-322.

43. Knibbe CA, Naber H, Aarts LP, Kuks PF, Danhof M. Long-term sedation with propofol $60 \mathrm{mg} \mathrm{mL}(-1)$ vs propofol $10 \mathrm{mg}(-1) \mathrm{ml}$ in critically ill, mechanically ventilated patients. Acta Anaesthesiol Scand 2004;48(3):302-307.

44. Nanas S, Angelopoulos E, Tsikriki S, Kritikos K, Voutsinas E, Zervakis D, et al. Propofol-induced hyperamylasaemia in a general intensive care unit. Anaesth Intensive Care 2007;35(6):920-923.

45. Otterspoor LC, Kalkman CJ, Cremer OL. Update on the propofol infusion syndrome in ICU management of patients with head injury. Curr Opin Anaesthesiol 2008;21(5):544-551.

46. Fudickar A, Bein B. Propofol infusion syndrome: update of clinical manifestation and pathophysiology. Minerva Anestesiol 2009;75(5): 339-344.

47. Hall RI, Sandham D, Cardinal P, Tweeddale M, Moher D, Wang X, et al. Propofol vs midazolam for ICU sedation: a Canadian multicenter randomized trial. Chest 2001;119(4):1151-1159.

48. Carson SS, Kress JP, Rodgers JE, Vinayak A, Campbell-Bright S, Levitt J, et al. A randomized trial of intermittent lorazepam versus propofol with daily interruption in mechanically ventilated patients. Crit Care Med 2006;34(5):1326-1332.

49. Ho KM, Ng JY. The use of propofol for medium and long-term sedation in critically ill adult patients: a meta-analysis. Intensive Care Med 2008;34(11):1969-1979.

50. Panzer O, Moitra V, Sladen RN. Pharmacology of sedative-analgesic agents: dexmedetomidine, remifentanil, ketamine, volatile anesthetics, and the role of peripheral mu antagonists. Crit Care Clin 2009;25(3):451-469; vii.

51. De Wolf AM, Fragen RJ, Avram MJ, Fitzgerald PC, Rahimi-Danesh F. The pharmacokinetics of dexmedetomidine in volunteers with severe renal impairment. Anesth Analg 2001;93(5):1205-1209.

52. Iirola T, Ihmsen H, Laitio R, Kentala E, Aantaa R, Kurvinen JP, et al. Population pharmacokinetics of dexmedetomidine during longterm sedation in intensive care patients. Br J Anaesth 2012;108(3): 460-468.

53. Precedex: full prescribing information. Lake Forest, IL: Hospira; Revised September 2010:EN-2680. http://www.precedex.com/ wp-content/uploads/Precedex_PI.pdf. Accessed March 21, 2013.

54. Shehabi Y, Ruettimann U, Adamson H, Innes R, Ickeringill M. Dexmedetomidine infusion for more than 24 hours in critically ill patients: sedative and cardiovascular effects. Intensive Care Med 2004;30(12):2188-2196.

55. Pandharipande PP, Pun BT, Herr DL, Maze M, Girard TD, Miller $\mathrm{RR}$, et al. Effect of sedation with dexmedetomidine vs lorazepam on acute brain dysfunction in mechanically ventilated patients: the MENDS randomized controlled trial. JAMA 2007;298(22):26442653.

56. Pandharipande PP, Sanders RD, Girard TD, McGrane S, Thompson JL, Shintani AK, et al. Effect of dexmedetomidine versus lorazepam on outcome in patients with sepsis: an a priori-designed analysis of the MENDS randomized controlled trial. Crit Care 2010; 14(2):R38

57. Riker RR, Shehabi Y, Bokesch PM, Ceraso D, Wisemandle W, Koura F, et al. Dexmedetomidine vs midazolam for sedation of 


\section{Sedation AND Paralysis}

critically ill patients: a randomized trial. JAMA 2009;301(5):489499.

58. Jakob SM, Ruokonen E, Grounds RM, Sarapohja T, Garratt C, Pocock SJ, et al. Dexmedetomidine vs midazolam or propofol for sedation during prolonged mechanical ventilation: two randomized controlled trials. JAMA 2012;307(11):1151-1160.

59. Dasta JF, Kane-Gill SL, Pencina M, Shehabi Y, Bokesch PM, Wisemandle $\mathrm{W}$, et al. A cost-minimization analysis of dexmedetomidine compared with midazolam for long-term sedation in the intensive care unit. Crit Care Med 2010;38(2):497-503.

60. Kollef MH, Levy NT, Ahrens TS, Schaiff R, Prentice D, Sherman G. The use of continuous i.v. sedation is associated with prolongation of mechanical ventilation. Chest 1998;114(2):541-548.

61. Kress JP, Pohlman AS, O'Connor MF, Hall JB. Daily interruption of sedative infusions in critically ill patients undergoing mechanical ventilation. N Engl J Med 2000;342(20):1471-1477.

62. Schweickert WD, Gehlbach BK, Pohlman AS, Hall JB, Kress JP. Daily interruption of sedative infusions and complications of critical illness in mechanically ventilated patients. Crit Care Med 2004; 32(6):1272-1276.

63. Girard TD, Kress JP, Fuchs BD, Thomason JW, Schweickert WD, Pun BT, et al. Efficacy and safety of a paired sedation and ventilator weaning protocol for mechanically ventilated patients in intensive care (Awakening and Breathing Controlled trial): a randomised controlled trial. Lancet 2008;371(9607):126-134.

64. Jackson JC, Girard TD, Gordon SM, Thompson JL, Shintani AK, Thomason JW, et al. Long-term cognitive and psychological outcomes in the awakening and breathing controlled trial. Am J Respir Crit Care Med 2010;182(2):183-191.

65. Schweickert WD, Pohlman MC, Pohlman AS, Nigos C, Pawlik AJ, Esbrook CL, et al. Early physical and occupational therapy in mechanically ventilated, critically ill patients: a randomised controlled trial. Lancet 2009;373(9678):1874-1882.

66. Pohlman MC, Schweickert WD, Pohlman AS, Nigos C, Pawlik AJ, Esbrook CL, et al. Feasibility of physical and occupational therapy beginning from initiation of mechanical ventilation. Crit Care Med 2010;38(11):2089-2094

67. Strøm T, Martinussen T, Toft P. A protocol of no sedation for critically ill patients receiving mechanical ventilation: a randomised trial. Lancet 2010;375(9713):475-480.

68. Marini JJ. Spontaneously regulated vs controlled ventilation of acute lung injury/acute respiratory distress syndrome. Curr Opin Crit Care 2011;17(1):24-29.

69. Gama de Abreu M, Guldner A, Pelosi P. Spontaneous breathing activity in acute lung injury and acute respiratory distress syndrome. Curr Opin Anaesthesiol 2012;25(2):148-155.

70. Slutsky AS. Neuromuscular blocking agents in ARDS. N Engl J Med 2010;363(12):1176-1180.

71. Sessler CN. Sedation, analgesia, and neuromuscular blockade for high-frequency oscillatory ventilation. Crit Care Med 2005;33(3 Suppl):S209-S216.

72. Arroliga A, Frutos-Vivar F, Hall J, Esteban A, Apezteguia C, Soto $\mathrm{L}$, et al. Use of sedatives and neuromuscular blockers in a cohort of patients receiving mechanical ventilation. Chest 2005;128(2):496506.

73. Raoof S, Goulet K, Esan A, Hess DR, Sessler CN. Severe hypoxemic respiratory failure: part 2: nonventilatory strategies. Chest 2010;137(6):1437-1448.

74. Schmidt UH, Hess DR. Does spontaneous breathing produce harm in patients with the acute respiratory distress syndrome? Respir Care 2010;55(6):784-786.

75. Schmidt U, Coppadoro A, Hess DR. To breathe or not to breathe? Crit Care Med 2012;40(5):1680-1681.
76. Murray MJ, Cowen J, DeBlock H, Erstad B, Gray AW, Jr., Tescher AN, et al. Clinical practice guidelines for sustained neuromuscular blockade in the adult critically ill patient. Crit Care Med 2002; 30(1):142-156.

77. Warr J, Thiboutot Z, Rose L, Mehta S, Burry LD. Current therapeutic uses, pharmacology, and clinical considerations of neuromuscular blocking agents for critically ill adults. Ann Pharmacother 2011;45(9):1116-1126.

78. Arroliga AC, Thompson BT, Ancukiewicz M, Gonzales JP, Guntupalli KK, Park PK, et al. Use of sedatives, opioids, and neuromuscular blocking agents in patients with acute lung injury and acute respiratory distress syndrome. Crit Care Med 2008;36(4): 1083-1088.

79. Leatherman JW, Fluegel WL, David WS, Davies SF, Iber C. Muscle weakness in mechanically ventilated patients with severe asthma. Am J Respir Crit Care Med 1996;153(5):1686-1690.

80. Behbehani NA, Al-Mane F, D’Yachkova Y, Pare P, FitzGerald JM. Myopathy following mechanical ventilation for acute severe asthma: the role of muscle relaxants and corticosteroids. Chest 1999; 115(6):1627-1631.

81. Garnacho-Montero J, Madrazo-Osuna J, Garcia-Garmendia JL, OrtizLeyba C, Jimenez-Jimenez FJ, Barrero-Almodovar A, et al. Critical illness polyneuropathy: risk factors and clinical consequences. A cohort study in septic patients. Intensive Care Med 2001;27(8):12881296.

82. Murray MJ, Brull SJ, Bolton CF. Brief review: nondepolarizing neuromuscular blocking drugs and critical illness myopathy. Can J Anaesth 2006;53(11):1148-1156.

83. Brunello AG, Haenggi M, Wigger O, Porta F, Takala J, Jakob SM. Usefulness of a clinical diagnosis of ICU-acquired paresis to predict outcome in patients with SIRS and acute respiratory failure. Intensive Care Med 2010;36(1):66-74.

84. de Letter MA, Schmitz PI, Visser LH, Verheul FA, Schellens RL, Op de Coul DA, et al. Risk factors for the development of polyneuropathy and myopathy in critically ill patients. Crit Care Med 2001;29(12):2281-2286.

85. De Jonghe B, Sharshar T, Lefaucheur JP, Authier FJ, Durand-Zaleski I, Boussarsar M, et al. Paresis acquired in the intensive care unit: a prospective multicenter study. JAMA 2002;288(22):2859-2867.

86. Ali NA, O'Brien JM, Jr., Hoffmann SP, Phillips G, Garland A, Finley JC, et al. Acquired weakness, handgrip strength, and mortality in critically ill patients. Am J Respir Crit Care Med 2008; 178(3):261-268.

87. Petrof BJ, Jaber S, Matecki S. Ventilator-induced diaphragmatic dysfunction. Curr Opin Crit Care 2010;16(1):19-25.

88. Tobin MJ, Laghi F, Jubran A. Narrative review: ventilator-induced respiratory muscle weakness. Ann Intern Med 2010;153(4):240-245.

89. Levine S, Nguyen T, Taylor N, Friscia ME, Budak MT, Rothenberg $\mathrm{P}$, et al. Rapid disuse atrophy of diaphragm fibers in mechanically ventilated humans. N Engl J Med 2008;358(13):1327-1335.

90. Forel JM, Roch A, Marin V, Michelet P, Demory D, Blache JL, et al. Neuromuscular blocking agents decrease inflammatory response in patients presenting with acute respiratory distress syndrome. Crit Care Med 2006;34(11):2749-2757.

91. Gainnier M, Roch A, Forel JM, Thirion X, Arnal JM, Donati S, et al. Effect of neuromuscular blocking agents on gas exchange in patients presenting with acute respiratory distress syndrome. Crit Care Med 2004;32(1):113-119.

92. Marik PE, Kaufman D. The effects of neuromuscular paralysis on systemic and splanchnic oxygen utilization in mechanically ventilated patients. Chest 1996;109(4):1038-1042.

93. Papazian L, Forel JM, Gacouin A, Penot-Ragon C, Perrin G, 
Loundou A, et al. Neuromuscular blockers in early acute respiratory distress syndrome. N Engl J Med 2010;363(12):1107-1116.

94. Marsch SC, Steiner L, Bucher E, Pargger H, Schumann M, Aebi T, et al. Succinylcholine versus rocuronium for rapid sequence intubation in intensive care: a prospective, randomized controlled trial. Crit Care 2011;15(4):R199.

95. Fodale V, Santamaria LB. Laudanosine, an atracurium and cisatracurium metabolite. Eur J Anaesthesiol 2002;19(7):466-473.

96. Vender JS, Szokol JW, Murphy GS, Nitsun M. Sedation, analgesia, and neuromuscular blockade in sepsis: an evidence-based review. Crit Care Med 2004;32(11 Suppl):S554-S561.

97. Sessler CN. Train-of-four to monitor neuromuscular blockade? Chest 2004;126(4):1018-1022.

98. Prielipp RC, Coursin DB, Scuderi PE, Bowton DL, Ford SR, Cardenas VJ Jr, et al. Comparison of the infusion requirements and recovery profiles of vecuronium and cisatracurium 51W89 in intensive care unit patients. Anesth Analg 1995;81(1):3-12.

99. Neto AS, Pereira VG, Esposito DC, Damasceno MC, Schultz MJ. Neuromuscular blocking agents in patients with acute respiratory distress syndrome: a summary of the current evidence from three randomized controlled trials. Ann Intensive Care 2012;2(1):33.

100. Derrington MC, Hindocha N. Measurement of evoked diaphragm twitch strength during anaesthesia. Adaptation and evaluation of an existing technique. Br J Anaesth 1988;61(3):270-278.

101. Donati F, Antzaka C, Bevan DR. Potency of pancuronium at the diaphragm and the adductor pollicis muscle in humans. Anesthesiology 1986;65(1):1-5.

102. Rudis MI, Sikora CA, Angus E, Peterson E, Popovich J, Jr., Hyzy $\mathrm{R}$, et al. A prospective, randomized, controlled evaluation of peripheral nerve stimulation versus standard clinical dosing of neuromuscular blocking agents in critically ill patients. Crit Care Med 1997;25(4):575-583.

103. Baumann MH, McAlpin BW, Brown K, Patel P, Ahmad I, Stewart $\mathrm{R}$, et al. A prospective randomized comparison of train-of-four monitoring and clinical assessment during continuous ICU cisatracurium paralysis. Chest 2004;126(4):1267-1273.

104. Yoshida T, Uchiyama A, Matsuura N, Mashimo T, Fujino Y. Spontaneous breathing during lung-protective ventilation in an experimental acute lung injury model: high transpulmonary pressure associated with strong spontaneous breathing effort may worsen lung injury. Crit Care Med 2012;40(5):1578-1585.

105. Barr J, Fraser GL, Puntillo K, Ely EW, Gelinas C, Dasta JF, et al. Clinical practice guidelines for the management of pain, agitation, and delirium in adult patients in the intensive care unit. Crit Care Med 2013;41(1):263-306.

\section{Discussion}

Gajic: Today steroids have been mentioned 2 or 3 times regarding their potential for interaction with NMBs to increase the risk for neuromyopathy. I think we need to dispel that myth. In a prospective phase of the Lazarus trial, ${ }^{1}$ during which myopathy was prospectively sought after, there was no difference in the incidence of neuromyopathy between patients treated with steroids or placebo. The effect of steroids on critical care neuromyopathy seems to be diminishing with better glucose control.

Schmidt: In general, I agree with you. What we don't know is the effect when combining steroids and muscle relaxants. If I remember right, in that trial there were not so many patients paralyzed. Most of the evidence about harm from steroids and muscle relaxants was obtained when the blood sugar level was in the 250 range, and at that time pancuronium, a steroidbased muscle relaxant, was mainly used. We don't know whether that's different from quinolone-based muscle relaxants such as cisatracurium. It's very difficult to assess the effects of steroids and muscle relaxants on neuromuscular weakness. Now blood sugar control is tighter and we use less steroids and muscle relaxants, and more shorter-acting muscle relaxants with different structures, such as cisatracurium. So in an era of tighter blood sugar control we might never have sufficient data on whether the combination of modern muscle relaxants and steroids contributes to critical care neuromyopathy.

Gajic: I give steroids only when absolutely necessary, to decrease lung inflammation in specific indications such as suspicion of drug-induced lung injury, acute eosinophilic pneumonia, and BOOP [bronchiolitis obliterans organizing pneumonia]. And you can use NMB to facilitate ventilator synchrony or decrease oxygen consumption, because the evidence of harm now is much less. I think we may be harming some patients by fearing the combined effect of steroids and neuromuscular blocking agents.

Schmidt: I absolutely agree.

MacIntyre: I think everybody here would agree that minimizing sedation is a good idea. This idea of a spontaneous awakening trial has taken on a life of its own and, if it's not already, it will soon be a reportable condition if you don't do spontaneous awakening trials. Is this really the only way to reduce sedation or optimize sedation?

Schmidt: Absolutely not. Maybe we've all had patients watching television and able to answer questions while on $50-100 \mathrm{mg} / \mathrm{h}$ of propofol. Especially young trauma patients become extremely agitated when they are totally off sedation, but when they're on low-dose propofol, they're often calm and interactive, so the socalled sedation holiday might not be appropriate for every patient.

Gajic: I think it's important to define that spontaneous awakening does not equal the interruption of continuous sedative infusion. If the patient's RASS is zero, no matter what they're taking, they're awake, not in a coma, and you have your awakening trial.

MacIntyre: That's an important point: completing a spontaneous breathing trial does not necessarily mean being 
off all sedatives. There's a lot of confusion out there on that.

Gajic: Especially with the newer drugs like dexmedetomidine and low-dose opiates, on which people are often fully awake on continuous infusions.

MacIntyre: There's also this notion that the patient should be off all sedation before taking the endotracheal tube out. I would like the anesthesia experts here to address that myth.

Schmidt: Yes, that's another myth. You don't have to. The pain medicine especially should continue, and they have to be breathing at least before you take it out, but, otherwise, no.

Marini: We use paralytics now very differently than we used to. Unmonitored infusion of paralytics is always dangerous, but with monitoring it usually works pretty well. Intermittent use of paralytics and closely observing the patient-letting them come closer to consciousness and movement and activity - almost surely is better tolerated than the way the data were collected back in the early 1990s. I think that most of us today think that the first few days of mechanical ventilation are crucial to the eventual outcome.

To me it makes perfect sense to let rogue inflammation settle out and let the body start to adapt to the new situation. In the early phase it makes a lot of sense to take control of the situation. These patients are terribly uncomfortable when they're intubated, due to their underlying disease and what we do to them. In that initial period, using monitored deep sedation and paralysis makes perfect sense. After the first 24 hours, when they start to "turn the corner," then you let them wake up and do as much as they can. That's another error we make: we layer our treatments over the sedatives far too long, and ignore that the patient has been making adaptations to the resolving disease. We might be turn- ing them into couch potatoes with what we do. Do you disagree?

Schmidt: No, I agree. The only thing is that it is very difficult to monitor pain and sedation correctly, because, unfortunately, all the scales we've mentioned are overlapping. Obviously, morphine and hydromorphone influence the RASS. We don't have good pain scales for deeply sedated and/or paralyzed patients; it's very hard to do.

When I give paralysis, when I do my monitoring, the patient may already be breathing before the twitches return. You see it in the operating room all the time: the patient has zero twitches, but the thoracic surgeon complains that they can see the diaphragm working, and the abdominal surgeon complains that the muscles are tightening up. This is a problem with the monitor; it's very difficult in practice. Outside of the research area it may not be very practical. I invite you anesthesiologists to disagree with me, but I believe it's better to have your hand on the patient's belly to see what they're doing on the ventilatordoing something or doing too muchinstead of relying on their cold hand, which is not really well perfused.

Marini: I don't like the infused approach either. I like intermittent activity.

Gajic: I think so too. I wish Papazian and colleagues ${ }^{2}$ titrated NMB according to ventilator synchrony rather than an arbitrary 48-hour infusion. Maybe somebody will do that. I think it will be important to sort out whether ventilator asynchrony and volutrauma are the key reasons that NMB is beneficial in early severe ARDS.

Kallet: I think it's important to recognize the studies that have shown that you do get pro-inflammatory cytokine release from the diaphragm when you flog it with an excessive workload. 3,4 That issue gets glossed over. Also, in the studies I've done on work of breathing and ARDS, where we tried to get patients sedated to a Ramsey score of 4 , they were triggering the ventilator with no problem. ${ }^{5}$ They were doing supernormal levels of work, particularly with tidal volumes of $6-8 \mathrm{~mL} / \mathrm{kg}$. The risk of diaphragmatic dysfunction in patients whose sedation and breathing frequencies are adjusted so they're basically triggering most of the time is, as far as I'm concerned, clinically not an issue.

Another thing I want to bring up, and I'd like some feedback, is that, as we'd say in San Francisco, we're getting too "Elton John" over dexmedetomidine. We're having problems with patients with status asthmaticus and severe ARDS, where they're not decreasing respiratory drive, and we can't get these patients oxygenated or in synchrony with the ventilator. It's an aggravating problem trying to get it through, even at the attending level, that in certain patient populations we need to get control of their respiratory drive and minimize it. I feel like I'm banging my head against the wall.

Schmidt: But here you're preaching to the choir.

Kallet: I just need the support.

Schmidt: You have support. I think the problem is that dexmedetomidine should not be used as a primary anesthetic. For the first few hours, maybe, with ARDS. Similar to a patient coming to the operating room and having a trauma and getting their belly sliced open; they are sick, they need to be controlled. With dexmedetomidine the idea is that the patient can interact with you. We talked about this this morning with Bob [Kacmarek]: this is not what the patient's body wants to do. This time maybe you have to do what your doctor tells you to do: be sedated and adequately ventilated. When you have a drug that only blunts your sympathetic in-flow, it's not the right drug for the situation. It's a great 
drug and it's changed what we're doing, but not for these severe patients who are triggering the ventilator constantly, because it gives you no or almost no respiratory depression. Maybe it's not useful in this situation, or you can add something to it and you're fine. You could do propofol and dexmedetomidine together.

Marini: The problem is that both propofol and dexmedetomidine are limited by heart-rate suppression in many people, and dexmedetomidine doesn't work for everybody. It's not like morphine, where you just up the dose. With dexmedetomidine you can go through the roof in dosage and heart rate can fall but the patient is not controlled: they're delirious.

\section{Schmidt: Agreed.}

Marini: What is this mechanism by which sedatives cause mental distortion that lasts into the indefinite future? I understand it's a point of concern, and I understand that post-pump mental dysfunction happens. But now we' re getting into the mindset of avoiding delirium at all costs, and "everybody gets bent out of shape after intensive care," and "what are we doing salvaging all these people with ARDS, because they're just going to be unhappy people afterwards?" You must be treating different people than I'm seeing. A lot of our patients are in the hospital for a long time, recover, and come back to clinic just fine, thank you very much. I think we should be concerned about it, but the case isn't proven.

Schmidt: I think you're right. In the delirium literature-and I apologize for being controversial, but I think it's allowed here-the first statement is that delirium is associated with in- creased mortality, but none of the delirium-prevention trials have ever shown to decrease mortality. So either our first assumption is wrong or our second assumption is wrong. The first assumption is that delirium is important for mortality, and the second is that we can do something about it; it may be something that will happen anyway. We might find something out about this.

In the MIND-USA study ${ }^{6}$ the idea is that critically ill patients who are ventilated and/or on pressors will be randomized to 3 different regimens. One is haloperidol, one is atypical, and the third is placebo. This might finally answer the question about delirium and mortality and long-term followup. It's really important, because this is a multicenter study; the rest were all from Vanderbilt. We might find out that (A) it's a problem but we can't do anything about it or treat it, and it might not happen as often as we think, or (B) we can treat it and we finally have an FDA approved treatment. At our current enrollment rate it will take at least 5 years to get any answers, so in 2017 I might be able to tell you what we should do.

Kallet: A correction: the first statement was not a fact, it was an assumption. The second part was an observable fact.

\section{Schmidt: Agreed.}

Kallet: Do you remember back in the early 1990s when folks, particularly our colleagues in nursing, were walking around with those big red pins that said "No Pain"? And back in the 1970s and 1980s most ventilated patients, unless they were direly ill, were awake. And I remember back in Syracuse, New York, we had people on CPAP of, like, $20 \mathrm{~cm} \mathrm{H}_{2} \mathrm{O}$; they were awake, and they seemed fine. It's the herd mentality. After the reports that pain was under-diagnosed and undertreated, everybody ended up on drips. I think we've kind of created our own problems, and we're trying to correct them. Unfortunately, I think we're going "Elton John" the other way.

Branson: What is this "Elton John" thing? Are you dissing him?

Kallet: Not at all, in terms of his music! It's some of his flamboyant wardrobe choices that are the joke. It's just a way of saying that something is outrageously "over the top."

\section{REFERENCES}

1. Steinberg KP, Hudson LD, Goodman RB, Hough CL, Lanken PN, Hyzy R, et al; National Heart, Lung, and Blood Institute ARDS Clinical Trials Network. Efficacy and safety of corticosteroids for persistent ARDS. N Engl J Med 2006;354(16):16711684.

2. Papazian L, Forel JM, Gacouin A, PenotRagon C, Perrin G, Loundou A, et al; ACURASYS Study Investigators. Neuromuscular blockers in early ARDS. N Engl J Med 2010;363(12):1107-1116.

3. Zhu E, Petrof BJ, Gea J, Comtois N, Grassino AE. Diaphragm muscle fiber injury after inspiratory resistive breathing. Am J Respir Crit Care Med 1997;155(3): 1110-1116.

4. Orozco-Levi M, Lloreta J, Minguella J, Serrano S, Broquetas JM, Gea J. Injury of the human diaphragm associated with exertion and COPD. Am J Respir Dis 2001; 164(9):1734-1739.

5. Kallet RH, Campbell AR, Dicker RA, Katz JA, Mackersie RC. Work of breathing during lung-protective ventilation in patients with acute lung injury and ARDS: a comparison between volume and pressureregulated breathing modes. Respir Care 2005;50(12):1623-1631.

6. Ely EW, Girard TD. Modifying the impact of ICU-associated neurological dysfunction: the MIND-USA Study. http://clinicaltrials.gov/ct2/show/NCT01211522. Accessed March 12, 2013. 